\title{
Duane Retraction Syndrome and Accompanying Ocular Abnormalities
}

\author{
Murat Kocamaz, ${ }^{1}$ (1) Ebru Demet Aygit, ${ }^{2}$ (D) Asli Inal, ${ }^{2}$ (1) Osman Bulut Ocak, ${ }^{2}$ (1) Ugur Cicek, ${ }^{3}$ \\ Birsen Gokyigit ${ }^{2}$
}

1Department of Ophthalmology, Darica Farabi Training and Research Hospital, Kocaeli, Turkey

${ }^{2}$ Department of Ophthalmology, University of Healty Sciences, Prof. Dr. N. Resat Belger Beyoglu Eye

Training and Research Hospital, Istanbul, Turkey

${ }^{3}$ Department of Ophthalmology, Siirt State Hospital, Siirt, Turkey

\begin{abstract}
Objectives: Duane retraction syndrome (DRS) is a congenital syndrome characterized by limitation in adduction and/or abduction eye movements and narrowing of the palpebral fissure in adduction, and may include globe retraction, upshoot or downshoot. Several systemic abnormalities, syndromes, and additional ocular findings can accompany DRS. This study is an evaluation of eye findings in patients with DRS.

Methods: The records of 632 patients with DRS who were followed up between 1995 and 2016 were reviewed retrospectively. Patients with a follow-up of less than 6 months and patients with a history of eye/cranial trauma or injury were not included in the study. Before the patients were examined, a detailed anamnesis was obtained. Details of the medical records, including additional systemic diseases, were recorded.

Results: The average of follow-up time was 45 months (min-max: 6-128 months). There were 255 male and 377 female patients. A total of 34 patients $(5.4 \%)$ had additional ocular abnormalities. The most frequently observed ocular pathologies associated with DRS were congenital ptosis $(n=6,0.94 \%)$ and coloboma of the iris $(n=4,0.63 \%)$.

Conclusion: Most cases of DRS are observed as isolated. However, various ocular and systemic abnormalities and syndromes are associated with DRS. In particular, synkinetic syndromes may frequently be seen alongside DRS. Therefore, a complete ocular examination and anamnesis are crucial in cases with DRS.
\end{abstract}

Keywords: Congenital ptosis, Duane retraction syndrome, iris coloboma, nystagmus.

\section{Introduction}

Duane retraction syndrome (DRS) is a congenital syndrome characterized by limitation in adduction and/or abduction eye movements and narrowing of the palpebral fissure in adduction, and may be accompanied by globe retraction, upshoot or downshoot. It was first described by Stilling and Turk. Alexander Duane published a series of 54 cases in 1905 and the syndrome was then named for Duane (I). DRS has been classified among the congenital cranial dysinnervation disorders (CCDD) (2). This group of disorders contains congenital, non-progressive, sporadic, and familial neuromuscular diseases (2). CCDD also includes congenital fibrosis of the extraocular muscles, congenital ptosis, Duane radial ray syndrome, horizontal gaze palsy with progressive scoliosis, congenital facial palsy, and Mobius syndrome.

Several systemic abnormalities, syndromes and ocular additional findings can accompany DRS. The objective of this study was to evaluate additional eye findings in patients with DRS. 


\section{Methods}

The medical records of 632 patients with DRS who were followed up between 1995 and 2016 at the Beyoğlu Eye Training and Research Hospital Pediatric Ophthalmology and Strabismus Unit were evaluated retrospectively. Before the patients were examined, a detailed anamnesis was obtained and all medical records and additional systemic diseases were analyzed. Patients with a follow-up of less than 6 months and patients with a history of eye/cranial trauma or injury were not included in the study. All cases underwent routine ophthalmological examinations including uncorrected and best corrected visual acuity, biomicroscopic examination, measurement of intraocular pressure and fundus examination. The angle of deviation in the primary position was measured with the Hirschberg test, Krimsky test, and prism cover test, as well as evaluation of eye movements in 9 diagnostic eye positions, head position and globe retraction, upshoot and downshoot, stereopsis, and binocular single vision. Cycloplegic refraction was performed on all patients with I\% cyclopentolate hydrochloride eye drops. Huber's classic classification was used to determine DSR subtypes. The research was conducted according to the tenets of the Declaration of Helsinki. Local ethics committee approval was obtained.

\section{Results}

A total of 632 of 34,809 patients with strabismus who consulted the Beyoglu Eye Research and Training Hospital between January 1995 and June 2016 were diagnosed with DRS, a rate of $1.81 \%$. The average patient follow-up time was 45 months (min-max: 6-128 months). The average age was I I. $3 \pm 9.4$ years (min-max: 6 months- 58 years). In all, 377 of the 632 patients (59.7\%) were female and 255 (40.3\%) were male. The left eye was affected in $45 \mathrm{I}$ patients (7I.4\%), the right eye was affected in 121 (19.2\%), and both eyes were affected in 60 patients (9.4\%). DRS type I was diagnosed in 55 I patients (87.2\%), 35 patients (5.5\%) had DRS type II, and 46 patients (7.3\%) had DRS type III.

In our study group, 3 I patients $(4.9 \%)$ had a history of esotropia among their first degree relatives, 15 patients $(2.3 \%)$ had a history of exotropia, 7 patients (I.I\%) had a history of nystagmus, 10 patients ( $1.6 \%$ ) had a history of anisometropic amblyopia, 5 patients $(0.8 \%)$ had a history of congenital ptosis, and 28 patients $(4.4 \%)$ had a history of DRS history (Table I).
The extra ocular pathologies encountered are summarized in Table 2: 6 patients had congenital ptosis, 2 patients had bilateral iris coloboma, 2 patients unilateral iris coloboma, 3 patients had nystagmus, 3 patients had ocular albinism and nystagmus, 2 patients had congenital cataract, 2 patients had Marcus Gunn jaw winking phenomenon, 2 patients had microcornea, 2 patients had crocodile tears syndrome, I patient had microphthalmia, I patient had distichiasis, I patient had heterochromia, I patient had a dermoid cyst, I patient had optic atrophy, I patient was diagnosed with ophthalmoplegic migraine, I patient had a persistent hyaloid artery, I patient had iris atrophy, and I patient had choroid coloboma. The most frequent ocular pathologies associated with DRS in this study group were congenital ptosis $(0.94 \%)$ and coloboma of iris $(0.63 \%)$. The overall rate of DRS patients in our study with additional ocular pathologies was $5.4 \%(n=34)$.

Table 2. Other ocular pathologies in Duane retraction syndrome patients

\section{Ocular findings} Number

Congenital ptosis 6

Coloboma of iris 4

Ocular albinism+nystagmus 3

Nystagmus 3

Congenital cataract $\quad 2$

Microcornea 2

Crocodile tears syndrome 2

Marcus Gunn Jaw Winking Phenomenon 2

Ophthalmoplegic migraine I

Dermoid cyst I

Optic atrophy

Distichiasis I

Heterochromia

Persistent hyaloid artery I

Retinopathy of prematurity I

Microophthalmia I

Atrophy of iris I

Choroid coloboma

Total $34(5.4 \%)$

Table I. Ocular pathologies in Duane retraction syndrome patient first degree relatives

Medical history Esotropia Exotropia Nystagmus Anisometropic amblyopia Congenital ptosis Duane retraction

syndrome

\begin{tabular}{lllllll}
\hline Number & 31 & 15 & 7 & 10 & 5 & 28 \\
$\%$ & 4.9 & 2.3 & 1.1 & 1.6 & 0.8 & 4.4 \\
\hline
\end{tabular}


Systemic pathologies associated with DRS were seen in 43 patients $(6.8 \%)$ in our study and the most common comorbid conditions were deafness $(0.6 \%, n=4)$, Down syndrome $(0.6 \%, n=4)$, and mental retardation and motor disability $(0.6 \%, n=4)$.

\section{Conclusion}

DRS is a strabismus syndrome characterized by congenital non-progressive ophthalmoplegia. Abduction and/or adduction are limited at birth. In addition, the globe may retract into the orbit in adduction, accompanied by narrowing of the palpebral fissure (3). Electrophysiological studies of DRS have demonstrated that innervation of the lateral rectus muscle by the oculomotor nerve causes the pathognomonic cocontraction of the medial and lateral rectus muscles (synkinesis phenomenon). DRS may also be seen with synkinesis phenomena, such as Marcus Gunn jaw winking phenomenon (due to aberrant trigeminal nerve innervation of the levator palpebrae superioris).

It is estimated that the incidence of DRS is approximately $1 \%$ of the total cases of strabismus (4). Kirkham (5) determined an incidence of DRS of $0.84 \%$ among 14.900 patients with strabismus. Ahluwalia (6) reported 20 patients (4\%) with ocular movement disorders among 500 with DRS. In our clinic the rate of patients with DRS among all strabismic patients was $1.81 \%$ (632 of 34.809 patients).

In $70 \%$ of patients with DRS, the syndrome is seen as isolated (7). However, ocular and systemic anomalies occur at a higher rate in DRS cases than in the normal population. DRS may be accompanied by skeletal, ear, genitourinary system, and nervous system disorders. There are reports in the literature of DRS cases observed in combination with Okihiro syndrome, Holt-Oram syndrome, Morning glory syndrome, Klippel-Feil syndrome, and Goldenhar syndrome (7). In our study, 4I (6.4\%) of the 632 patients with DRS had systemic abnormalities: deafness $(n=4,0.63 \%)$, Down syndrome $(n=4$, $0.63 \%)$, and mental retardation with motor disability $(n=4$, $0.63 \%$ ) were the most commonly seen pathologies. In our case series, the syndromes most often seen accompanying DRS were Down syndrome $(n=4)$, CHARGE syndrome $(n=I)$, Goldenhar syndrome $(n=I)$, and VACTERL association $(n=I)$.

The rate of ocular anomalies with DRS has been reported as $3.1 \%$ to $13.9 \%$ in the literature $(4,8,9)$. Pfaffenbach $(10)$ detected a rate of ocular anomalies with DRS of $8.18 \%$, while Maruo (II) reported $13.9 \%$. In our study, the rate of ocular anomalies in patients with DRS was determined to be $5.4 \%$ $(n=34)$, which was consistent with literature data.

Nystagmus, congenital ptosis, crocodile tears syndrome, Marcus-Gunn jaw winking phenomenon, congenital cataract, optical nerve hypoplasy, and heterochromia have been re- ported as the most often seen pathologies associated with DRS in the literature $(10,12)$. Pfaffenbach $(10)$ determined that among I 86 DRS patients, there was accompanying nystagmus, epibulbar dermoid, anisocoria, and ptosis, and that nystagmus was the most common ocular pathology associated with DRS. O'Malley (12) reported 3 cases of optic disc coloboma and I of Goldenhar syndrome in 97 patients with DRS.

Reports of synkinetic syndromes accompanying DRS in the literature support the potential role of neurological abnormalities in the etiology $(9,13)$.

Recent studies have demonstrated that abducens nucleus hypoplasia or the complete absence in cases of DRS $(14,15)$. Gupta (16) observed the absence of or hypoplasia of the sixth nerve in 5 of 7 eyes with DRS (7I.42\%). These results particularly suggest a role of the brain stem in the etiology of DRS $(14,15)$. Furthermore, findings of crocodile tears syndrome, vestibulo-ocular reflex, and optokinetic nystagmus reinforce the assumption that DRS is a brainstem anomaly (17). The association between Marcus Gunn jaw winking phenomenon and DRS also suggests that peripheral misinnervation is a common finding in both diseases (18). In addition, monocular elevation deficiency, congenital extraocular muscle fibrosis, and pseudo inferior oblique overactivity with Marcus Gunn jaw winking phenomenon have been shown to coexist (19). In our study, 2 patients had crocodile tears syndrome, 2 patients had Marcus Gunn jaw winking phenomenon, and 6 patients had nystagmus.

Varma (20) described an association between crocodile tears syndrome, mental retardation, and spina bifida occulta with DRS in a case report (20). D'amelio (2I) reported an association between DRS and nystagmus with a patterned hyperpigmentation of the retinal pigment epithelium, developmental delay, micro- and pachygyria, and craniopharyngioma. Skiker et al. (22) reported crocodile tears syndrome, preauricular tags, and Hirschsprung disease in a case with DRS. Shauly (23) reported a case with ptosis in his retrospective study of 4 I patients with DRS. Khan (24) described isolated congenital ptosis and DRS with synergistic divergence and recessive COL25AI mutations. The most common ocular pathology accompanying DRS in our study group of 632 patients was congenital ptosis: 6 (0.94\%).

The retrospective design of this study is the primary limitation; the family history and systemic disease records may be incomplete. The strength of the study is that it is one of only a few in the literature to evaluate ocular abnormalities accompanying DRS in such a large series of patients.

In conclusion, DRS is a complex, congenital syndrome. The clinical features may include adduction and/or abduction limitation in eye movements, narrowing of the palpebral aperture in adduction effort, globe retraction, and upshot or downshoot in the affected eye. Neurological and genetic 
factors can play a role in the etiology and various systemic and ocular findings have been associated with the syndrome. Findings accompanying DRS, such as crocodile tears syndrome, Marcus Gunn jaw winking phenomenon, and nystagmus, support the theory that DRS is a brainstem anomaly. A detailed anamnesis from the patient and thorough ocular and systemic examinations are important in the treatment and follow-up of patients with DRS.

\section{Disclosures}

Peer-review: Externally peer-reviewed.

Conflict of Interest: None declared.

Financial Disclosure: This retrospective study was not supported by any company. None of the authors has financial or proprietary interests in any material or method mentioned. These data have not been previously published.

Authorship Contributions: Involved in design and conduct of the study (MK, EDA); preparation and review of the study (MK, EDA); data collection (MK, EDA, AI, OBO, UC, BG); and statistical analysis (MK, EDA).

\section{References}

I. DeRespinis PA, Caputo AR, Wagner RS, Guo S. Duane's retraction syndrome. Surv Ophthalmol 1993;38:257-88. [CrossRef]

2. Singh A, Pandey PK, Agrawal A, Mittal SK, Rana KM, Bahuguna C. Congenital cranial dysinnervation disorders. Int Ophthalmol 2017;37:1369-8I. [CrossRef]

3. Von Norden GK. Special forms of strabismus, in binocular vision and ocular motility. 6th ed. Bologna: Mosby; p. 458-66.

4. Gurwood AS, Terrigno CA. Duane's retraction syndrome: literature review. Optometry 2000;71:722-6.

5. Kirkham TH. Duane's syndrome and familial perceptive deafness. Br J Ophthalmol 1969;53:335-9. [CrossRef]

6. Ahluwalia BK, Gupta NC, Goel SR, Khurana AK. Study of Duane's retraction syndrome. Acta Ophthalmol 1988;66:728-30. [CrossRef]

7. Gutowski NJ. Duane's syndrome. Eur J Neurol 2000;7:145-9.

8. Chung M, Stout JT, Borchert MS. Clinical diversity of hereditary Duane's retraction syndrome. Ophthalmology 2000; 107:500-3.

9. Oltmanns $M$, Khuddus $N$. Duane retraction syndrome type I, Marcus Gunn jaw-winking and crocodile tears in the same eye. J Pediatr Ophthalmol Strabismus 2010;47. [CrossRef]

10. Pfaffenbach DD, Cross HE, Kearns TP. Congenital anomalies in Duane's retraction syndrome. Arch Ophthalmol 1972;88:635-9.
I I. Maruo T, Kubota N, Arimoto H, Kikuchi R. Duane's syndrome. Jpn J Ophthalmol 1979;23:453-68.

I2. O'Malley ER, Helveston EM, Ellis FD. Duane's retraction syndrome - plus. J Pediatr Ophthalmol Strabismus 1982; 19:16I-5.

13. Ramsay J, Taylor D. Congenital crocodile tears: a key to the aetiology of Duane's syndrome. Br J Ophthalmol. 1980;64:5I8-22.

14. Miller NR, Kiel SM, Green WR, Clark AW. Unilateral Duane's retraction syndrome (Type I). Arch Ophthalmol 1982;100:1468-72.

15. Hotchkiss MG, Miller NR, Clark AW, Green WR. Bilateral Duane's retraction syndrome. A clinical-pathologic case report. Arch Ophthalmol 1980;98:870-4. [CrossRef]

16. Gupta C, Sharma P, Saxena R, Garg A, Sharma S. Clinical correlation of imaging findings in congenital cranial dysinnervation disorders involving abducens nerve. Indian J Ophthalmol 2017;65:155-159. [CrossRef]

17. Saad N, Lee J. Medial rectus electromyographic abnormalities in Duane syndrome. J Pediatr Ophthalmol Strabismus 1993;30:88-91.

18. Isenberg S, Blechman B. Marcus Gunn jaw winking and Duane's retraction syndrome. J Pediatr Ophthalmol Strabismus 1983;20:235-7.

19. Shah AD, Kumar AB, Kothari K. Bilateral Marcus Gunn jaw winking synkinesis with monocular elevation deficiency: a case report and literature review. Int Ophthalmol 2012;32:199-20I.

20. Varma C, Aroor S, Mundkur SC, Annamalai K. Bilateral type-I duane syndrome with multiple anamolies: a case report. J Clin Diagn Res 2012;6:1435-6. [CrossRef]

2I. D'Amelio S, Lassen N, Vasiliou V, Bateman JB. Duane retraction syndrome, nystagmus, retinal pigment epitheliopathy and epiretinal membrane with micro- and pachygyria, developmental delay, hearing loss and craniopharyngioma. Ophthalmic Genet 2009;30:7-12. [CrossRef]

22. Skiker H, Laghmari M, Cherkaoui O, Lachgar R, Daoudi R. Bilateral Duane syndrome associated with crocodile tears, and congenital megacolon: a case study. [Article in French]. J Fr Ophtalmol 2008;31:e6. [CrossRef]

23. Shauly Y, Weissman A, Meyer E. Ocular and systemic characteristics of Duane syndrome. J Pediatr Ophthalmol Strabismus 1993;30:178-83.

24. Khan AO, Al-Mesfer S. Recessive COL25AI mutations cause isolated congenital ptosis or exotropic Duane syndrome with synergistic divergence. J AAPOS 20I5;19:463-5. [CrossRef] 